\title{
Favouring Small and Medium Sized Enterprises with Directive 2014/24/EU?
}

\author{
Martin Trybus and Marta Andrecka* \\ This article argues that the four main measures introduced in the 2014 reform of the Pro- \\ curement Directives to promote Small and Medium Sized Enterprises (SMEs) cannot be \\ classified as measures favouring SMEs. A measure favours SMEs when it compromises the \\ main objectives of competition, non-discrimination and value for money. The discussion \\ covers the regimes on the division of larger contracts into lots, the European Single Procure- \\ ment Document (ESPD), minimum turnover requirements, and direct payments to subcon- \\ tractors.
}

\section{Introduction}

Small and Medium Sized Enterprises (SME) are the dominant life form in the economies of all EU Member States. 20.8 million SMEs were registered in the then 27 EU Member States in 2011. They amounted to $99.8 \%$ of all enterprises and contributed more than half of the Union's GDP. ${ }^{1}$ Their share of public contracts, however, is often deemed insufficient. In contrast to old Directive 2004/18/EC, Public Sector Directive 2014/24/EU ${ }^{2}$ includes measures designed - not to directly increase the proportion of SMEs being

\subsection{2/epppl/2017/3/6}

* Martin Trybus, Professor of European Law and Policy and Director, Institute of European Law at the Birmingham Law School, University of Birmingham, United Kingdom, E-Mail: $<$ m.trybus@bham.ac.uk>. Thanks to L Butler, R Dragneva, and MA Corvaglia (Birmingham), F Lichère (Aix-en-Provence), and $M$ Stachowiak (Warsaw) and the participants of the CEVIA conference Procurement beyond price: Sustainability and CSR in public purchasing, 4-5 May 2017 in Copenhagen for comments. All remaining errors are the sole responsibility of the authors. Martin Trybus covered sections I-III and VI; Marta Andrecka, Assistant Professor at the Centre for Enterprise Liability (CEVIA), Faculty of Law, University of Copenhagen, Denmark, E-Mail: <marta.andrecka@jur.ku.dk>. The article is a contribution to the author's research project funded by the Carlsberg Foundation and a contribution to CEVIA's project on Public-Private Enterprise Liability funded by the Danish Research Council for Independent Research. Marta Andrecka covered sections IV and V.

1 G Wessel Thomassen et al., SME's access to public procurement markets and aggregation of demand in the EU, PwC, ICF-GHK and ECORYS, Study commissioned by the European Commission, Directorate General for Internal Market and Services, Brussels, February 2014, 5.

2 Directive 2014/24/EU of the European Parliament and of the Council of 26 February 2014 on public procurement and repealing Directive 2004/18/EC [2014] OJ L94/65. For overviews of this Directive, see F Lichère, R Caranta and S Treumer (eds), Modernising Public Procurement: The New Directive (Djøf: Copen- awarded public contracts - but to improve their tendering conditions and thereby facilitate and encourage and thus increase their participation in public procurement procedures. Thus, the Directive contains four main 'innovations' directed at increasing SME participation in public procurement: the division of contracts into lots (III.), the European Single Procurement Document (IV.), the limitation of requirements for participation (V.), and direct payments to subcontractors (VI.). ${ }^{3}$ Directive 2014/24/EU also introduced a number of additional measures for SMEs in less obvious places. ${ }^{4}$

hagen, 2014); Directive 2014/24/EU is part of the 2014 procurement reform package which also includes two further Directives: Directive 2014/25/EU of the European Parliament and of the Council of 26 February 2014 on procurement by entities operating in the water, energy, transport and postal services sectors and repealing Directive 2004/17/EC [2014] OJ L94/243 and Directive 2014/23/EU of the European Parliament and of the Council of 26 February 2014 on the award of concession contracts [2014] OJ L94/1; For an overview of the reform, see R Caranta, 'The changes to the public contract directives and the story they tell about how EU law works' (2015) 52 CML Rev, 391-459; Issues 3 and 4 of the (2014) 23 PPL Rev; and G Skovgaard Ølykke and A Sánchez Graells (eds), Reformation or Deformation of the EU Public Procurement Rules in 2014 (Edward Elgar: Cheltenham 2016).

3 The promotion of SMEs has also been high on the agenda in the UK where, more than a year before the April 2016 deadline, the UK Public Contracts Regulations 2015 transposed most of the EU measures, and, following the proposals of Lord Young (Growing Your Business: A Report on Growing Micro Businesses, The Second Part of the Report on Small Firms, May 2013, 19-23) additionally abolished Pre-Qualification Questionnaires for contracts below the thresholds, and established the single contract portal 'contracts-finder', available at <https://www.gov.uk/ contracts-finder $>$ (last accessed on 20 July 2017) to promote SME participation and success in public procurement.

4 These refer to large scale dynamic purchasing systems (Recital 66), time limits (Recital 80), design contests (Recital 120) and thresholds (Recital 134). Moreover, SME are mentioned for exam- 
Filling a gap in the literature regarding the use of public procurement regulation to promote SMEs in general and the innovations of Directive 2014/24/EU in this matter in particular, this article will provide a short legal analysis of these four 'European' SME regimes to address the basic question whether they can be considered as measures favouring SMEs through public procurement. The question is not whether these regimes amount to a legal framework that makes SME promotion a sustainable goal, as the introduction of four new techniques expressly intended to promote SMEs clearly makes SME participation an objective of Directive 2014/24/EU, an intention clearly declared in Recital 124. The analysis will be based on the understanding that a measure for the promotion of SMEs in public procurement constitutes a regime favouring ${ }^{5}$ SMEs when the procurement rules are adjusted for that purpose to an extent that compromises the primary objectives of competition and value for money, of the contracting authority procuring what it needs to operate at the best possible terms. ${ }^{6}$ With regards to the EU Procurement Directives, a provision favouring SMEs would also compromise their specific primary objectives of non-discrimination (on grounds of nationality) and equal treatment. ${ }^{7}$ A provision clearly favouring SMEs to an extent that the primary objectives are compromised would be, for example, provisions comparable to those of the US Small Businesses Act requiring a minimum number of SMEs to be selected in competitive procedures, ${ }^{8}$ or procurement procedures limited to SMEs comparable to the reserved contracts for sheltered workshops now regulated in Article 20 of Directive 2014/24/EU. ${ }^{9}$ Another example would be a margin of preference for SMEs at the contract award stage comparable to the "targeted procurement" in favour of previously disadvantaged businesses in post-Apartheid South Africa. ${ }^{10}$ Competition would be limited by either excluding or disadvantaging large companies in favour of SMEs. In contrast, what Burgi calls "SME-fair"11 or "SME-friendly"12 measures and what Lichère calls measures "facilitating SME access"13 aim to increase competition by levelling the playing field by addressing the specific problems that often prevent or compromise their participation. This differentiation is important because the introduction of SME favouring measures would represent a considerable change - away from the primary objectives, whereas merely facilitating SME access does not compromise the primary objectives. Based on this understanding, it will be argued that, with the exception of a few details, the four SME-friendly ple in Recital 59 where the Commission calls for the monitoring of the aggregation of demand as a practice that has the potential to disadvantage SMEs. According to Susie Smith, who discussed this matter with the author in late September 2016, large scale dynamic purchasing systems appear to prove a particularly effective regime to increase SME participation in the UK. Promoting SMEs through public procurement is a long-standing policy of the EU, see inter alia: SMEs Participation in Public Procurement in the European Community SEC(1992) 722; European Commission Action Programme for SMEs COM(1986) 445 final; Public Procurement: Regional and Social Aspects COM(1989) 400 final; Promoting SME Participation in the Community COM(1990) 166 final.

5 F Lichère, 'L'accès PME dans la Directive 2014/24' in Y Marique and K Wauters (eds), EU Directive 2014/24 on Public Procurement: A New Turn for Competition in Public Markets? (Larcier: Brussels 2016), 110, uses the equivalent French term "favoriser" and considers the division into lots and the reserved contracts for disabled workshops as examples but does not consider the former a measure promoting secondary objectives.

6 See the differentiation between "SME-fair" and "SME-favouring" in M Burgi, 'Small and medium-sized enterprises and procurement law' (2007) 15 PPL Rev, 287-288.

7 Thanks to Luke Butler for discussing this with Martin Trybus based on an earlier version of this article.

8 See also the judgment of the French Conseil d'Etat of 9 July 2007, $n^{\circ} 297711$, ruling against a provision of the 2006 Code de Marchés Publics (Public Procurement Act) allowing contracting authorities to select a minimum number of SMEs at the bid stage as violating the principles of non-discrimination and equal treat- ment. Thanks to François Lichère for pointing this out to Martin Trybus when commenting on an earlier draft of this article; $\mathrm{S}$ Saussier, 'L'accès PME aux marches publics: une analyse économique' (2009), available at <http://www.webssa.net/files/ MARCHEPUB-VFINALE.pdf> (last accessed on 18 July 2017), 1, reports that a quota for SMEs was even considered in France (President Sarkozy in his lettre de mission to Finance Minister Lagarde). In a contribution for the brochure for the Public Procurement Week 2017 in London, Chris Hoyle, Deputy Director of the Complex Transactions Team at the Cabinet Office, writes of the possibility for the post-Brexit UK to "positively discriminate in their [SMEs] favour" (p. 13).

9 Article 38 Utilities Procurement Directive 2014/25/EU is an equivalent provision.

10 Ministry of Finance \& Ministry of Public Works, Green Paper on Public Sector Procurement Reform in South Africa (Pretoria, April 1997) and the Small Enterprises Development Agency SEDA.

11 Burgi (n 6), 297-288

12 M Burgi, 'Mittelstandsfreundliche Vergabe - Möglichkeiten und Grenzen (Teil I)' (2006) 17 Neue Zeitschrift für Bau- und Vergaberecht, 606-610: The German term "mittelstandsfreundliche Vergabe" is to be translated as 'SME-friendly'. However, in the introduction on page 606 Burgi uses the term mittelstandsgerechte Auftragsvergabe which is to be translated as 'SME-fair'. The latter term is preferable because it merely suggests levelling the playing field whereas the earlier term suggests a certain degree of preference, which is precisely not what it aims to describe.

13 Lichère (n 5), 110. 
regimes of Directive 2014/24/EU are not measures favouring SMEs.

\section{Background}

There is no universally accepted definition of an SME and the precise understanding of the concept also varies in the Member States. ${ }^{14}$ However, for its purposes Article 83(3) of Directive 2014/24/EU adopted Commission Recommendation 2003/361/EC, which defines SMEs as enterprises with up to 250 employees and an annual turnover of up to $€_{50}$ million and/or an annual balance sheet total not exceeding $€ 43$ million. ${ }^{15} \mathrm{~A}$ further differentiation is provided with definitions of micro-, ${ }^{16}$ small-, ${ }^{17}$ and mediumsize enterprises. ${ }^{18}$ This definition is used for the purposes of this article. ${ }^{19}$

A problem caused by any measures promoting SME participation, in addition to the danger of national or even regional protectionism, ${ }^{20}$ is that such measures will make the applicable procurement law more complicated and therefore less user-friendly and prone to violations and litigation. This can be a deterrence for SME participation in itself. ${ }^{21}$ Moreover, these measures can lead to additional costs. Related to these problems, the promotion of SMEs is often classified as a secondary, ${ }^{22}$ sustainable, ${ }^{23}$ horizontal, ${ }^{24}$ or strategic objective or goal, ${ }^{25}$ as a 'community benefit', ${ }^{26}$ akin to social or environmental ${ }^{27}$ considerations in public procurement. While there is strong support for the use of public procurement to promote 'secondary' considerations, ${ }^{28}$ these are objectives in addition to and possibly compromising the primary objective of public procurement, which is to provide the public authority with the supplies and services it needs to operate, connected to value for money and non-discrimination objectives and the 'vehicles' of competition and transparency to achieve them. ${ }^{29} \mathrm{~A}$ conflict arises inter alia when the economically most advantageous tender is not awarded the contract or the costs of the procedure are higher because of the 'horizontal' objective. The promotion of SMEs could be seen as a 'secondary' objective because

14 See for example, on the German definitions, M Werner, "'Los" oder "Nicht-Los" - das ist hier die Frage! Zur Mittelstandsklausel

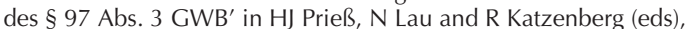
Wettbewerb - Transparenz - Gleichbehandlung: 15 Jahre Vergaberecht, Festschrift for Fridhelm Marx (C. H. Beck: Munich 2013), 806-807: Werner cites especially the Federal Court of Appeal (Bundesgerichtshof) in BGH NJW, 1992, 1039 in which the Court ruled that there are "ultimately no useful criteria" for the definition of an SME, especially rejecting the criteria of the number of employees.

15 Article 2(1) of Title I of the Annex to Commission Recommendation 2003/361/EC of 6 May 2003 concerning the definition of micro, small and medium-sized enterprises [2003] OJ L124/36.

16 Ibid., Article 2(3): "an enterprise which employs fewer than 10 persons and whose annual turnover and/or annual balance sheet total does not exceed EUR 2 million."

17 Article 2(2) Recommendation 2003/361/EC: "an enterprise which employs fewer than 50 persons and whose annual turnover and/or annual balance sheet total does not exceed EUR 10 million".

18 The limit of Article 2(1) Recommendation 2003/361/EC; These definitions are also used in the UK, see the Lord Young report, Make Business Your Business: Supporting the Start-up and Development of Small Business (First Part of the Report on Small Firms), May 2012, 2

19 Werner (n 14), 806, criticises the SME definition of the Recommendation as adding little for procurement law as originating in EU State aid law. A further discussion of the various definitions, however, would go beyond the aims of this article.

20 E Ruh, 'Mittelstandsbeteiligung an öffentlichen Aufträgen' (2005) 5 Vergaberecht, 735 , reports that $80 \%$ of the turnover of the SMEs who returned his questionnaire is made within $20 \mathrm{~km}$ from the seat of the company. Promoting SME thus often means promoting domestic SMEs and even SMEs from the same region as the contracting authority.

21 Saussier (n 8), 9.

22 This term is used inter alia in by M Burgi, D Dragos et al. and G Racca in their chapters in R Caranta and M Trybus (eds), The Law of Green and Social Procurement (Djøf: Copenhagen 2010).

23 The chapters of R Caranta, S Treumer, L Vidal, M Spyra, J Gonzaléz Garcia and M Trybus in R Caranta and M Trybus, ibid., use this term.

24 This term was coined by S Arrowsmith and P Kunzlik in the chapter 'Public procurement and horizontal policies in EC law: general principles' in their edited collection Social and Environmental Policies in EC Procurement Law (Cambridge: CUP 2009).

25 This term is used inter alia in W Kahlenborn et al., Strategic Use of Public Procurement in Europe (Final Report to the European Commission, MARKT/2010/02/C 2011)

26 This term was used in a session of the 2015 Procurement Week organised by the University of Bangor and the Welsh Government in Cardiff in March 2015.

27 See Caranta/Trybus (n 22).

28 See inter alia C McCrudden, Buying Social Justice. Equality, Government Procurement and Legal Change (Oxford: OUP, 2007); Arrowsmith/Kunzlik (n 24); S Arrowsmith, 'Horizontal Policies in Public Procurement: A Taxonomy' (2010) 10 Journal of Public Procurement, 149; P Kunzlik, 'Green Public Procurement-European Law, Environmental Standards and 'What to Buy' Decisions' (2013) 25 Journal of Environmental Law, 173; A Semple, A Practical Guide to Public Procurement (Oxford: OUP 2015); and the contributions in Caranta/Trybus (n 22).

29 On the objectives of public procurement regulation see the short yet seminal article of S Schooner, 'Desiderata: Objectives for a System of Government Contract Law' (2002) 11 PPL Rev, 99-102 or S Arrowsmith, J Linarelli and D Wallace Jr., Regulating Public Procurement: National and International Perspectives (London: Kluwer Law International 2000), chapter 1, 27-32. 
these enterprises create considerably more employment than large companies, the promotion of employment clearly being a secondary or strategic objective, and thus promoting SMEs means promoting employment. ${ }^{30}$ Moreover, the promotion of SMEs is often intended to promote local economies; smaller companies are frequently local companies, and 'local' almost inevitably means national. ${ }^{31}$ This implies protectionism which cannot be reconciled with the Internal Market.

Traditionally the Court of Justice established a rather restrictive approach to the use of public procurement to promote secondary objectives. ${ }^{32}$ Thus, procurement rules promoting strategic objectives including SME participation must be reconcilable with the primary objectives, especially non-discrimination and competition..$^{33}$ It is not least for this reason that the old Public Sector Directive 2004/18/EC did not contain many adjustments to promote $\mathrm{SMEs}^{34}$ and the Commission initially addressed SMEs with soft law. ${ }^{35}$ However, the protectionist aspect of the objective has to be put into perspective: not all SMEs can be seen as only local and therefore national enterprises. The division into lots discussed below, for example, may well lead to, for example, more Moravian SMEs bidding for smaller contracts in Bavaria, Lower Austria, or Upper Silesia.

The economic importance of SMEs has an impact on the discussion of whether the promotion of SMEs is seen as a secondary or horizontal or strategic objective of public procurement regulation at all. The Germans, for example, traditionally more reserved about these objectives, which they used to call 'aspects alien to procurement', ${ }^{36}$ see SME promotion as a separate issue. ${ }^{37}$ More SME participation in public contracts could increase competition through a wider

30 According to Financing SMEs and Entrepreneurs 2012: An OECD Scoreboard (OECD Publishing: Paris 2012), 76, 91, 119 and 153 respectively, $60.5 \%$ of the workforce in France, $80 \%$ of the workforce in Italy, and $72 \%$ of the workforce in Portugal are employed by SMEs. SMEs generate the majority of new job creation; for a recent assessment, see PW Wright et al., 'Job Creation, Job Destruction and the Role of Small Firms: Firm-Level Evidence for the UK' (2010) 72 Oxford Bulletin of Economics and Statistics, 621-647; see also Recital 124 Directive 2014/24/EU pointing out that "given the potential of SMEs for job creation, growth and innovation it is important to encourage their participation in public procurement [...]."; see also S Schoenmaekers, 'The role of SMEs in promoting sustainable procurement' in B Sjåfjell and A Wiesbrock (eds), Sustainable Public Procurement under EU Law (Cambridge: CUP 2016), 160-181.

31 That means with the exception, to an extent, of deeply integrated border regions of two or more Member States, such as the Belgian-Dutch-German region around Maastricht-Aachen. The danger of SME-friendly polices to foster an anti-competitive or anti-free movement effect is acknowledged by Lichère ( $\mathrm{n}$ 5), 119.

32 See inter alia Case C-513/99 Concordia Bus Finland v. Helsinki Kaupunki [2002] ECR I-7213; Case C-448/01 EVN Wienstrom AG v. Austria [2003] ECR I-14521; Case C-31/87 Gebroeders Beentjes v. The Netherlands [1988] ECR I-4365; Case C-225/98 Commission v. France (Nord Pas de Calais) [2000] ECR I-4475; see also S Arrowsmith, The Law of Public and Utilities Procurement. Regulation in the $E U$ and the UK, Vol. 1 ( $3^{\text {rd }}$ edition, London: Sweet \& Maxwell 2014), 8 and 1256-93; and PA Trepte, Regulating Procurement. Understanding the Ends and Means of Public Procurement Regulation (Oxford: OUP 2004), 168-76. However, there is some evidence to demonstrate CJEU's shift towards the allowance of pursuing broader sustainable objectives; see CJEU's more recent ruling in Case C-115/14 RegioPost GmbH \& Co. KG $\checkmark$ Stadt Landau in der Pfalz, (RegioPost) [2015] ECLI-760, upholding the minimum wage clause; and Case C-368/10 Commission v Netherlands (Dutch Coffee) [2012] ECLI-284, allowing to address social considerations such as fair trade in award criteria.

33 A Sánchez Graells, in 'Truly competitive public procurement as a Europe 2020 lever: what role for the principle of competition in moderating horizontal policies', paper delivered at the UACES Conference, 9 September 2015, in Bilbao, highlights that "[o]therwise, it risks diminishing its own effectiveness and efficiency due to the incompatibility of such extraneous considerations" and cites SL Schooner, 'Commercial Purchasing: The Chasm between

the United States Government's Evolving Policy and Practice' in S Arrowsmith and M Trybus (eds), Public Procurement: The Continuing Revolution (The Hague: Kluwer Law International 2003), 159 , and also reminds us that "[t]his has been warned for a long time" citing C Turpin, Government Procurement and Contracts (Essex: Longman 1989), 67. For extended discussion and further references to this academic debate, see also A Sánchez Graells, Public Procurement and the EU Competition Rules ( $2^{\text {nd }}$ edition, Hart: Oxford 2015), 101-104.

34 Recital 32 Directive 2004/18/EC wants to "encourage the involvement of small and medium-sized undertakings in the public contracts procurement market," but to that end only considers that "it is advisable to include provisions on subcontracting." The emphasis on subcontracting is confirmed by the provisions on subcontracting in Articles 25 and 60, the remainder of the instrument not containing any SME relevant provisions, apart from the aggregation rule in Article discussed below; Lichère (n 5), 110.

35 European Commission, European Code of Best Practices Facilitating Access by SMEs to Public Procurement Contracts, Staff Working Document SEC(2008) 2191.

36 Translated by Martin Trybus from the German original vergabefremde Aspekte.

37 See M Burgi, 'Secondary Considerations in Public Procurement in Germany', Caranta/Trybus (n 22), 105-142, at 136-138: The promotion (Förderung) of SMEs features prominently in the procurement laws of some of the German States (Länder), see inter alia, § 6(1) Hessisches Vergabegesetz vom 5 März 2013 (GVBI. 6/2013 S. 121); §§ 1(1) and 4 Gesetz über die Vergabe öffentlicher Aufträge in Mecklenburg-Vorpommern(Vergabegesetz Mecklenburg-Vorpommern - VgG M-V)vom 7. Juli 2011 GVOBI. M-V 2011, S. 411; or § 3 Gesetz über die Vergabe öffentlicher Aufträge in Sachsen-Anhalt (Landesvergabegesetz - LVG LSA) vom 19. November 2012 GVBI. LSA 2012, 536. The traditional negative attitude towards 'secondary objectives' appears to have changed. At the $17^{\text {th }}$ Forum Vergabe Gespräche in Fulda (Germany) in April 2015, the main German procurement conference, the relevant presentations considered 'nachhaltige Vergabe' (sustainable procurement) as the new consensus. See as examples for a strong emphasis on secondary considerations: Berliner Ausschreibungsund Vergabegesetz (BerlAVG) vom 08.07.2010 (GVBI. S. 399 vom 22.07.2010), most recently amended by the Erste Gesetz zur Änderung des Berliner Ausschreibungs- und Vergabegesetzes vom 05.06.2012 (GVBI. S. 159 vom 16.06.2012). 
and more innovative supplier and provider base and thus have an effect on the objective of value for money. ${ }^{38}$ Economic theory supports this positive effect on competition, and also emphasises that specialised SMEs can be more efficient on certain contracts or contract parts requiring their specialism, and that their participation makes collusion between the big companies more complicated. ${ }^{39}$

Moreover, since in contrast to large companies SMEs exist in all and especially also the smaller Member States, the participation of these companies has also an Internal Market dimension, furthering the free movement of goods and services (including works) in all Member States. In other words, it promotes a European procurement market not just for big business in big Member States. However, SMEs create proportionately more employment than large companies, train more people, provide economic stability even during an economic crisis, and are loyal to the regions in which they are based. ${ }^{40}$ For all these reasons, which as Burgi rightly points out are difficult or impossible to quantify, ${ }^{41}$ SMEs are close to the heart of politicians in all the Member States, as shown inter alia by the references to SMEs in Articles 158(2)(b), 173(1) and 179(2) TFEU. ${ }^{42}$ Nevertheless, these reasons are more in line with secondary or horizontal objectives and explain why, as in this article, the promotion of SME participation in public procurement is often also discussed as a sustainable goal.

38 Burgi (n 12), 607

39 See V Grimm, R Pacini, G Spagnolo, and M Zanza, 'Division into lots and competition in procurement', chapter 7, in N Dimitri, G Piga and G Spagnolo (eds), Handbook of Procurement (Cambridge: CUP 2006), 179-180; Saussier (n 8), 2; Unless SMEs become implicit in collusion. SMEs are just as prone to collusion as big companies. In fact, they may be more so as a matter of economic necessity. Thanks to Luke Butler for pointing this out when commenting on an earlier version of this article.

40 Burgi (n 6), 285.

41 Burgi (n 12), 607, who also cites H Willems, Die Förderung des Mittelstands: Wirtschaftsverfassungsrechtliche Legitimation und Vergaberechtliche Realisierung (Carl Heymanns: Cologne 2003), 56 , for a systematic documentation of the political motivations for SME fairness.

42 These are Treaty articles which require the unanimous approval of all Member States.

43 M Linthorst, J Telgen and F Schotanus, 'Buying bundles: the effects of bundling attributes on the value of bundling' Proceedings of the 2008 International Procurement Conference in Amsterdam, define the term 'undividable' as undividable for buyer's markets, which they explain by example: "Consider buying a bundle of electricity for two office buildings. According to the definition this will be a bundle of two products; you can find a supplier willing to deliver electricity for one of your office locations. Buying electricity for a part of an office building would be

\section{Division into Lots}

A public contract can be awarded as a single contract to only one prime contractor or it can be divided into several smaller parts or lots which are then awarded separately and possibly to different contractors. A procurement can involve the award of a contract for a complete airport, for example. Alternatively, that contract can be divided into lots, say one for the construction of the terminal, another for the construction of the runways, and yet another one for all electrical appliances, and so on. Public contracts can be divided into lots until any resulting lot becomes undividable. ${ }^{43}$ Lots can be homogeneous ${ }^{44}$ and heterogeneous. ${ }^{45} \mathrm{Re}-$ garding the number of lots, there is some evidence indicating that a division into many lots (more than 10) considerably increases the participation and chances of micro- and small companies of being awarded the contract. In contrast, the division into only a few lots (2-4) reduces participation from small, medium-sized, and large enterprises and only increases participation and chances of micro-companies. ${ }^{46}$ Additionally, the size of the lots determines which companies have sufficient capacity to bid for at least one lot. ${ }^{47}$ However, awarding a single large contract lowers administrative $\operatorname{costs}^{48}$ and increases buying power ${ }^{49}$ and economies of scale. ${ }^{50}$ Moreover, division might undermine the effectiveness of procurement when it is not technically or economically feasible or when the number of

much harder, because no markets exist for supplying electricity to parts of office buildings. So the undividable product of the bundle is one office building" (p. 4).

44 Each lot consists of the same product (for example cars or cleaning services).

45 Each lot consists of a different product, for example when the contracts for a new airport is divided into different lots for the construction of the building, doors, electrical appliances, windows, toilets, etc

46 J Stake, 'SME Participation and Success in Public Procurement' (Södertörn University 2014), 23.

47 See Grimm/Pacini/Spagnolo/Zanza (n 39), 168, 180.

48 A Loman, F Ruffini and L de Boer, 'Designing ordering and inventory management methodologies for purchased parts' (2002) 38 Journal of Supply Chain Management, 22-29; On the additional costs, see RP McAfee and J McMillan, Incentives in Government Contracting (Toronto: TUP 1987), 57-60.

49 J Ramsay, 'The resource based perspective, rents, and purchasing's contribution to sustainable competitive advantage' (2001) 37 Journal of Supply Chain Management, 38-47; VA Mabert and T Schönherr, 'An online RFQ system: a case study' (2001) 5 Practix, $1-6$.

50 L Birou, SE Fawcett and GM Magnan, 'Integrating product life cycle and purchasing strategies' (1997) 33 Journal of Purchasing and Materials Management, 23-31. 
size of the lots is not geared towards the market in which they are to generate competition. Reasons not to divide into lots include that the different components of a contract are highly dependent on each other or when there is a need to coordinate them. ${ }^{51}$

\section{Article 46 of Directive 2014/24/EU}

Different to the old Directive 2004/18/EC, Article 46(1) of Directive 2014/24/EU provides that contracting authorities may award contracts divided into separate lots while they are free to determine the size and subject-matter of such lots. ${ }^{52}$ This is clearly intended as a technique to promote SME participation in public procurement. ${ }^{53}$ According to Article 46(4), Member States may also require rather than just allow the division into separate lots in their national laws transposing the Directive. ${ }^{54}$ However, in cases in which this has not been made obligatory by the transposing national law ${ }^{55}$ or when not dividing into lots is allowed in certain cases, ${ }^{56}$ contracting authorities shall indicate the main reasons for their decision not to divide into lots. This means that the division into lots is the default approach suggested by the Directive and Member States have the option to make this obligatory for all or parts of the contracts subject to the Directive and their transposing national laws.

However, the new Directive does not require the division into lots, although the decision not to divide

51 Linthorst/Telgen/Schotanus (n 43), 10.

52 See also the very similar Article 65 of Utilities Directive 2014/25/EU.

53 Recital 78 of Directive 2014/24/EC reads: "Such division could be done on a quantitative basis, making the size of the individual contracts better correspond to the capacity of SMEs, or on a qualitative basis, in accordance with the different trades and specialisations involved, to adapt the content of the individual contracts more closely to the specialised sectors of SMEs or in accordance with different subsequent project phases"

54 Also Article 65(4) Utilities Directive 2014/25/EU; see the old Article 10 CMP 2006 (France) and old §97(3) GWB (Germany), see below, after the transposition of Directive 2014/24/EC, Article 32 Ordonnance $n^{\circ}$ 2015-899 du 23 juillet 2015 (France) and \$97(4) GWB 2016 (Germany) respectively.

55 Regulation 46 [UK] Public Contracts Regulations 2015, Regulation 46 [Irish] European Union (Award of Public Authority Contracts) Regulations 2016 and §22 [Austrian] BVergG 2006, as amended in 2016.

56 Article 32 II. Ordonnance $n^{\circ}$ 2015-899 du 23 juillet 2015.

57 S Smith, 'Practical Issues of division into lots (divide and explain principle)' at the Public Procurement: Global Revolution VII conference in Nottingham, 16 June 2015.

58 Emphasis added. a contract into lots requires a communication of the reasons: the "divide or explain principle". ${ }^{57}$ This raises many questions in Member States (such as the UK) that have opted for divide or explain in their transposing laws. How difficult is it not to divide and explain? Does there have to be a good 'excuse' or is 'explaining' merely a formality that can be satisfied by providing 'cut and paste' generic reasons? Can the decision not to divide and explain be subject to judicial review in the Member State or through an enforcement action against the Member State? However, these largely open questions do not impact on the research question of this article, since as argued below, not even the compulsory division into lots qualifies as a measure favouring SMEs.

\section{Lot Bundling}

According to Article 46(2), the transposing national laws may provide that bids "may be submitted for one, for several or for all of the lots" of a divided contract (lot bundling). However, "even where tenders may be submitted for several or all lots, [the contracting authority may] limit the number of lots that may be awarded to one tenderer" ${ }^{58}$ Furthermore, according to Article 46(3) the transposing legislation may provide that "more than one lot may be awarded to the same tenderer," and that "contracting authorities may award contracts combining several or all lots." The transparency requirements that come with these paragraphs essentially provide that the contract notice must state how many bids for how many lots are allowed. Thus Article 46(2)-(3) allows the use of several approaches. Limiting lot bundling can amount to a measure favouring SMEs because larger companies cannot benefit from their advantages (economies of scale) leading to higher prices for individual lots. However, such an approach is possible but not required by the Directive and might even be left to be decided by contracting authorities. Whether an approach on lot bundling represents a regime favouring SMEs thus depends on transposition and practice.

\section{Alternative Bids}

It is not clear whether Article 46 allows a bidder to make different bids for each lot on the one hand and a different and probably lower one if he or she is 
awarded all or several lots on the other hand (alternative bids). In other words, it is not clear whether Article 46(2) allows a bidder to offer a rebate if awarded several or all lots. ${ }^{59}$ It could be argued that prohibiting rebates goes beyond a SME-friendly levelling of the playing field. Rebates affect the question of whether a procurement law favours SMEs to an extent that negatively affects value for money. Not allowing the described rebate would be an SME favouring measure since in the end a (significantly) higher price could be paid for the contract as a whole. ${ }^{60}$ It is argued that this would go against the objectives of Article 46 for the same reason. If rebates can be offered for all the lots then the SMEs for which the contract has been divided will be priced out of the competition, thereby undermining the objectives of the division into lots. However, the Directive ${ }^{61}$ is not clear on this question and a judgment of the Court of Justice might be required and it is possible the Court would rule against rebates as they undermine the SME-friendly purpose of Article 46. France, as Lichère reports "surprisingly", 62 allowed the previously banned alternative bids in its 2016 transposing legislation. ${ }^{63}$ Lichère also points out, that allowing alternative bids with rebates is good for the public purse but less so for SMEs. ${ }^{64}$ He argues that if the French legislator really wanted to favour SMEs they better revert to the prohibition of alternative bids, although this would take economies of scale out of public contracts. ${ }^{65}$ Thus, this old French approach to alternative bids represented a measure favouring
SMEs. It is remarkable that the new Directive with its SME-friendly objectives appears to have led to the repeal of an SME favouring measure. However, this also proves how low the level of harmonisation actually is: Member States are left with considerable legislative discretion.

\section{Favouring SMEs?}

Overall, it is argued that for reasons related to division into lots regimes in general and to Article 46 in particular, the division into lots regime in Article 46 of Directive 2014/24/EU cannot be classified as a regime favouring SMEs. In comparison to the award of one large contract, dividing it into lots will often cause extra costs, for example, through additional staff time. However, competitive procurement procedures also have this effect in comparison to single source procurement. Competition created by competitive procurement procedures will regularly more than compensate for the additional costs and effort involved. The additional competition created by the facilitation of SME participation ${ }^{66}$ will regularly have a similar effect. The devil is in the detail, namely in the rules on bundling and alternative bids. As both appear to be allowed, the competition through the participation of larger companies who can use their advantages can be maintained. These details are important to ensure that SMEs can participate in addition rather than instead of large companies,
59 Thanks to François Lichère for bringing this issue to the attention of Martin Trybus when commenting on an earlier draft of this article.

60 However, Article 10 of the old French CMP 2006 expressly prohibited such a rebate as favouring larger companies. Article 10 (1) sentence 3 Code des Marchés Publics 2006: "Les candidats ne peuvent présenter des offres variables selon le nombre de lots susceptibles d'être obtenus." [English: "Bidders shall not submit variant offers for the lots they are bidding for." Translation of the author]. This issue is not addressed in \$97(3) of the old German GWB.

61 Nor is the European Code of Best Practices, SEC(2008) 2193, 7-8 (Recital 78 Directive 2014/24/EU still recommends the use of this document).

62 Lichère (n 5), 112.

63 Article 32 I. para 4 Ordonnance $n^{\circ}$ 2015-899 du 23 juillet 2015 reads: "Les offres sont appréciées lot par lot sauf lorsque l'acheteur a autorisé les opérateurs économiques à présenter des offres variables selon le nombre de lots susceptibles d'être obtenus [emphasis added]." Neither \$97(4) GWB 2016 nor \$30 $\mathrm{VgV}$ clarify whether alternative bids are allowed in Germany and
Regulation 46 [UK] Public Contracts Regulations does not address the question.

64 Lichère (n 5), 112.

65 Ibid.

66 L Carpineti, G Piga and M Zanza, 'The Variety of Procurement Practice: Evidence from Public Procurement' in Dimitri/Piga/Spagnolo (n 39), 23-24; C Bovis, EC Public Procurement Law (London: Longman 1997), 117; Burgi (n 6), 293-294;

Grimm/Pacini/Spagnolo/Zanza (n 39), 179; McAfee/McMillan (n 48), 57-60; Sánchez Graells (n 34), 348-349, citing recent empirical support for this effect: M Amaral, S Saussier and A YvrandeBillon, 'Expected Number of Bidders and Winning Bids: Evidence form the London Bus Tendering Model' (2013) 47 Journal of Transport and Economic Policy, 17-34, and also citing J de Brux and C Desireux, 'To allot or not to Allot Public Services? An Incomplete Contract Approach' (2014) 37 European Journal of Law and Economics, 455-476, emphasising the positive effects of competition for contracting authorities; Saussier (n 8), 12, points out that in many sectors the response rate is so low and as a consequence competition so limited that an increase in SME participation can be expected to have tangible effects on competition and thus drives prices down. 
thereby ensuring an increase in competition. If an increase in competition and thus lower prices and other economic advantages can be achieved, then value for money is enhanced and not compromised, as would be the case most importantly with reserved contracts.

Moreover, the level of harmonisation is set too low for Article 46 itself to qualify as a measure favouring SMEs. Only the transposition of Article 46 may have this effect, possibly through an excessively rigid regime of compulsory division and especially by limitations of lot bundling and alternative bids. Such approaches to transposition are possible due to the low intensity of harmonisation and lack of clarity in certain aspects. However, it would be national legislative decisions and not EU harmonisation which would compromise competition and thus constitute a measure favouring SMEs.

\section{The European Single Procurement Document (ESPD)}

One of the main challenges of SMEs participation in public procurement are the significant costs and administrative burden associated with the documentation required for the qualification stage of the procurement process. ${ }^{67}$ These obstacles derive from the obligation of economic operators to provide docu-

67 European Commission, Green Paper on Modernisation of EU Public Procurement Policy: Towards More Efficient European Procurement Market, Working paper, Synthesis of Replies at 6, 4 and 15; $M$ Trybus, 'The Promotion of Small and Medium-Sized Enterprises in Public Procurement: A Strategic Objective of the New Public Sector Directive' in F Lichère, R Caranta and S Treumer (eds), Modernising Public Procurement: The New Directive (Copenhagen: Djøf 2014), 266-267.

68 Article 59 of Directive 2014/24/EU.

69 Both electronic and paper versions of the ESPD may exist until 18 April 2018.

70 The limitation of ESPD is acknowledged in Recital 84 from which it follows that ESDP is not to remove but to "limit [...] major obstacle to [...] participation in public procurement".

71 Already before the introduction of the ESPD in some Member States, a variation of standardised selection stage document existed, see self-declaration in France, Portugal, Spain, Germany, Nordic countries or Pre-Qualification Questionnaire (PQQ) in the United Kingdom. However, the issue has been that these national standardised documents systems were not harmonised across the $\mathrm{EU}$, creating therefore obstacles for economic operators wishing to compete for cross-border procurements.

72 European Commission Implementing Regulation 2016/7, January 2016 establishing the standard form for the European Single Procurement Document, Annex I [2016] OJ L 3/16-34. mentary evidence of their compliance with tender terms and conditions at the very beginning of the procurement procedure. The ESPD was introduced inter alia to resolve these issues, ${ }^{68}$ as a part of a wider European public procurement reform aimed at simplification, red tape reduction, and streamlining the documentation requirements. ${ }^{69}$ The ESPD is not strictly intended as an instrument to promote SMEs participation in public procurement - a reduction in red tape would also relieve larger bidders. The ambition of the legislator was for the ESPD to simplify cross-border procurement and help providing access to new opportunities for businesses, including SMEs. ${ }^{70}$ However, larger companies have the resources to deal with red tape giving them an advantage over SMEs which do not or less so. Therefore, a reduction of red tape could facilitate the participation of SMEs by levelling the playing field without disadvantaging large companies, except through the increased competition. In order to ascertain whether it is a measure favouring SMEs it is necessary to look at some details of the ESDP regime.

\section{Features of the ESDP}

The ESPD is a standard self-declaration designed as a 'one size fits all' blueprint which, in principle, an economic operator completes once and can reuse in any future tender. It replaces the obligation of presenting originals of all pre-qualification documents and represents a means of preliminary evidence for the bidder meeting the tender requirements (exclusion grounds [Article 57]; selection criteria [Article 58]; reliance on third party capacities [Article 63]; and criteria for reducing the number of qualified candidates [Article 65]). ${ }^{71}$ The ESPD is divided into six parts which shall include information regarding: 1) procurement procedure and contracting authority; 2) economic operator; 3) exclusion criteria; 4) selection criteria; 5) reduction of the number of qualified candidates; and 6) concluding statements. ${ }^{72}$ As all six parts make cross-references to the procurement documents, in practice the ESPD will need to be completed for each procurement individually. Thus, the ESDP is failing in its ambition to be a single standard for multiple procurements. This may be particularly the case when a procurement is to include aspects such as lots, subcontracting, or relying on third party capabilities, or all of these, or a variation of 
them. ${ }^{73}$ When a public contract is to be divided into lots, a specific ESPD is to be provided for each lot. If the contract is to include subcontracting, a contracting authority may require subcontractors to complete appropriate parts of their own ESPDs. ${ }^{74}$ If the bidder relies on third party capabilities, each third party will need to complete its own separate ESPD.

The completed ESPD is to be submitted with the tender in open procedures, or with the request to participate in other procurement procedures. ${ }^{75}$ Only the successful bidder is then to submit 'without delay ${ }^{176}$ the updated, full supporting documentation, on the request of the contracting authority, before the award of the contract. ${ }^{77}$ The successful bidder is not required to provide the full documentation if that can be acquired "directly by accessing a national database in any Member State that is available free of charge, such as the national procurement register, a virtual company dossier, an electronic document storage system, or a prequalification system", or when the contracting authority already possesses these documents. The ESPD service is integrated with E-Certis, a free online mapping tool used to identify and compare certificates requested in public procurement procedures across the EU. It is not obligatory for contracting authorities to request an ESPD, but there is a clear obligation to accept a submitted ESPD as a preliminary and sufficient evidence of its compliance with the procurement terms and conditions. $^{78}$

\section{A Shift of Costs and Burden Away from Economic Operators?}

It is argued that the ESPD leads to additional costs, administrative burden, and increase in complexity in procurement procedures for the contracting authorities. Thus, it is questionable whether simplification and cost savings can be achieved on both sides of the procurement relationship. Rather, a transfer of the related costs and obligations from the economic operator to the contracting authority takes place. Contracting authorities now have to locate the relevant information among the copies of documents they already possess or in freely available databases. ${ }^{79}$ Telles welcomes this shift as an incentive for contracting authorities to request only the necessary documents, as they will bear the costs and have to make the effort, rather than the economic operators, as before $2014 .{ }^{80}$ However, this shift of burden creates several challenges.

Firstly, the contracting authority needs to conduct 'intelligence' work to acquire the necessary information. For example, the ESPD includes a new obligation derived from Article 59 to ensure that no person serving on the economic operator's administrative, management and supervisory bodies, or with powers of representation, decision or control therein, has been the subject of a conviction of crimes such as corruption, fraud, terrorism, child labour, etc. ${ }^{81}$ The contracting authority must check the criminal records of members of the successful bidder. The process of verification is often resource-intensive and may potentially introduce unequal treatment among economic operators. The latter follows from the fact that in some Member States there is no criminal records database (such as the UK). Therefore, the ESPD will need to suffice, while in other Member States economic operators need to present multiple excerpts of criminal records, while bearing the increased costs of participation. If the criminal records need to be checked for large framework agreements then this will require resources of personnel and time. Contracting authorities must obtain permission in writing from the economic operator to retrieve the records of relevant persons working for the latter. Due to issues of data protection and privacy, such records cannot be copied or sent via email. The contracting authority can only check the records, but it cannot store them for a longer peri-

73 P Telles, 'The European Single Procurement Document' (2017) 4 Upphandlingsrättslig Tidskrift, 6.

74 Implementing Regulation (n 71); Article 71(5) 3 of Directive 2014/24/EU.

75 Article 59(1) of Directive 2014/24/EU

76 There is no certainty what 'without delay' constitutes. The Directive is silent on how much time is needed to fulfil the discretion of 'without delay' which may pose challenges in practice.

77 Article 59(4-8); Article 60 and where appropriate Article 62 of Directive 2014/24/EU.

78 Article 59 Directive 2014/24/EU; see also GM Racca, 'Electronic Qualitative Selection of Economic Operators: the challenge of the European Single Procurement Document (ESPD)' in M Burgi, M Trybus and S Treumer (eds), Qualification, Selection and Exclusion in EU Procurement (Copenhagen: Djøf 2016), 303-325.

79 Article 59(5) of Directive 2014/24/EU.

80 Telles (n 72), 10.

81 Article 57 Directive 2014/24/EU. 
od. Consequently, the records must be either destroyed or returned to the economic operator or a special digital form of data sharing will have to be introduced. According to a Finnish practitioner, the complexity of the process is counter-productive, as the bidders prefer a visit to the contracting authority to show the original records - tangibly - rather than take advantage of the benefits of digitalisation. $^{82}$

Another related issue regards the documents contracting authorities 'already possess'. If the contracting authority is a small organisation there seems to be no problem in identifying the correct file. However, if the contracting authority has many departments simultaneously conducting various procurements, locating the documents may be both challenging and time-consuming, unless a proper record keeping system is in place. Not to mention that it may be problematic to asses if the information included in such documents is updated or if it is not defective in some way, e.g. whether the names of the company's representatives on the submitted documents correspond with the current certificate of incorporation or whether all the licenses or certificates are still valid. ${ }^{83}$

82 M Turunen, 'Sometimes I feel like I am Sherlock', blog post available at <https://www.hansel.fi/blogi/2017/05/16/sometimes-i -feel-i-am-sherlock/> Last accessed on 20 July 2017.

83 A Semple, A Practical Guide to Public Procurement (Oxford: OUP 2015), 103.

84 The failure of the economic operator to provide the necessary documentation as evidence for the self-declarations made in the ESPD constitute a discretionary ground for exclusion (Article 57 (4)(h)), which the contracting authority can apply any time (Article 57(5)).

85 On serious misrepresentation when supplying information requested by the contracting authority, see Case C-387/14 Esaprojekt [2017] ECLI-338.

86 In practice, there may be lack of incentive on the side of contracting authorities, due to the used resources and cost. Similar lack of incentive is present in cases of sustainable procurement performance clauses. Even when they are not respected, contracting authorities rarely if at all terminate the contract. View presented by A Piening at the conference Procurement beyond price: Sustainability and CSR in public purchasing, 4-5 May 2017 in Copenhagen referring to the real life example of handling a SKI framework agreement clauses violation by Dell; See: Danwatch, Case study of labour conditions at 4 Dell suppliers in China.

87 Semple (n 82), 103

88 A Sánchez Graells and P Telles, 'Commentary to the Regulation $59^{\prime}$ (2016) blog post on Public Contracts Regulations 2015, available at $<$ http://pcr2015.uk/regulations/regulation-59 -european-single-procurement-document/> Last accessed on 20 July 2017.
Secondly, the use of the ESPD introduces a risk of non-compliance with the principle of equal treatment in the context of two-stage procurement processes. An economic operator may be admitted to the tender stage even if it does not meet the relevant selection criteria as the ESPD shifts the stage of assessing documentation from the beginning of the procedure to the last stage of the procurement process. In the worst case scenario, after a long procurement process (i.e. competitive dialogue), a contracting authority may find itself in a situation where the successful bidder proves to be ineligible. ${ }^{84}$ This may be due to the provision of false (fraudulent) or inaccurate information, or failure to meet requirements the economic operator only thought it meets. ${ }^{85}$ This scenario is particularly risky as it may lead to a waste of time and resources, potentially requiring repetition of at least part of the procurement process. Alternatively, the contracting authority may be tempted to turn a blind eye to a lack of compliance with selection criteria to escape the need of retendering or terminating the procurement procedure. ${ }^{86}$ These risks seem to be acknowledged by the EU legislator in Recital 84, where it is stated that in twostage procedures contracting authorities may require original documentation at the selection stage. Article 59(4) establishes that contracting authorities retain the right of requesting the originals of the documents at their discretion, which may be helpful in the context of two-stage procedures.

Thirdly, the ESPD was expected to reduce the administrative burden. The reason why the achievement of this objective is questionable is due to the possible argument that the self-declaration introduces a new layer of complexity for the contracting authorities. The ESPD makes it more difficult for contracting authorities to apply relevant selection criteria as it limits their discretion: they have to rely on a 'one-size-fits-all' ESPD form and try to fit all types of procurement into it, without due regard to the frequently arising necessity of more specific and elaborated documentation requirements. ${ }^{87}$ This 'fitting and adjusting' exercise may lead to delays in procurement, due to the need for further clarifications. ${ }^{88}$

\section{Favouring SMEs?}

It is debatable if the ESPD rules can be classified as favouring SMEs. Although the provision contributes, 
to some extent, to the contracting authorities' costs, administrative burden, and the complexity of procurement procedures, this is more than compensated for by the gains through increased competition. Moreover, the ESDP is part of the broader reform towards simplification and digitalisation of procurement in general, and not solely for the promotion of SMEs. Furthermore, the costs, administrative burden, and complexity are possibly only a temporary phenomenon, until contracting authorities learn how to use the new tool and until harmonised, digitalised systems are in place. Finally, it could be argued that the negative impact of the ESPD on contracting authorities stems from inappropriate practices rather than interpreting the rules as part of a move towards favouring SMEs. Contracting authorities are likely to learn and adapt and in the process, most of the costs, administrative burden, and complexity will gradually be reduced.

\section{The Minimum Turnover Requirement (Cap)}

Article 58 includes a list of possible requirements for participation in procurement procedures. These concern the suitability of the bidders to pursue the relevant professional activity, their economic and financial standing, and their technical and professional ability. Until recently, contracting authorities exercised a 'fair degree' of discretion when establishing turnover requirements. ${ }^{89}$ The only limitations of that discretion followed from the need to consider the specifics of the particular contract, and to respect the proportionality principle. $^{90}$ Specifying particularly onerous economic and financial standing criteria may lead to diminished competition or block the access of SMEs to procurement markets. ${ }^{91}$ Moreover, financial requirements, especially the burdensome minimal turnover, have been over-used by contracting authorities in the past, thus hindering SME participation in public procurement. ${ }^{92}$ SMEs' size, limited financial resources and access to financing makes bidding above certain turnover requirements too risky or simply impossible. Recital 83 acknowledges this effect by noting that:

overly demanding requirements concerning economic and financial capacity frequently constitute an unjustified obstacle to the involvement of SMEs in public procurement. Any such requirements should be related and proportionate to the subjectmatter of the contract.

\section{The Cap}

To address and mitigate this issue, Article 58 (3) introduces a new cap limiting minimum turnover requirements to a maximum of twice the contract value. The introduction of this provision is clearly intended as a method of promoting SMEs participation in public procurement. It follows from the assessment of the EU procurement reform process. At first, the Commission had proposed to introduce a higher turnover cap of three times the contract value. ${ }^{93}$ Then, based on the report from the Committee on the Internal Market and Consumer Protection (IM$\mathrm{CO})$ the provision on turnover was reduced to the current level. ${ }^{94}$ Based on an assessment of the contract award notices for above the thresholds contracts published on TED in 2012, reducing the turnover criteria from thrice to twice the contract value appears to open a sizeable new market tranche (improvement of $8 \%$ participation) for 'typical' micro-enterprises. ${ }^{95}$ Considering that SME organisations such as UEAPME had demanded for a turnover requirement cap of five times the contract value, ${ }^{96}$ the final ver-

89 See joined Cases C-27-29/86 CEI \& Bellini, judgment of 9 July 1987, ECR I-3347, [26-28]; Case 31/87 Beentjes [1988] ECR I-4635, [17]; Case C-315/01 Gesellschaft für AbfallentsorgungsTechnik GmbH (GAT) and Österreichische Autobahnen und Schnellstraßen AG (ÖSAG) [2003] ECR I-6351, [61].

90 Article 18 of Directive 2014/24/EU.

91 Turnover requirements have been already identified as 'formidable obstacles' to access procurement market by SME[s] in Proposal for Procurement Directive, $\operatorname{COM}(2011) 896$ final, at 11.

92 See French judgement of the Conseil d'Etat CE of 9 July 2007, Syndicat EGF-BTP, no297711; CE 29 Nov. 2006, Agence nationale pour l'emploi, n'290712; see further F Lichère, 'Qualification, Selection and Exclusion of Economic Operator under French Public Procurement Law' in Burgi/Treumer/Trybus (n 77), 41-61; Sánchez Graells/Telles (n 87).

93 Article 56(3) Proposal for Procurement Directive, COM(2011) 896 final.

94 Amendment 177, Report from the Committee on the Internal Market and Consumer Protection (IMCO) of the European Parliament on the proposal for a Directive on public procurement [C7-0006/2012], 11 January 2013.

95 European Parliament, Potential impact on SMEs of certain EP amendments to two proposed Public Procurement Directives, (PE 507.505 IAAM-2013-1), 26.

96 UEAPME, Position Paper: UEAPME reply to the green paper consultation on the modernisation of EU public procurement policy "Towards a more efficient European Procurement Market" (2011), available at <http://ueapme.com/IMG/pdf/110414_PP _greenpaper_final.pdf $>$ Last accessed on 20 July 2017. 
sion of Directive 2014/24/EU by far exceeded SMEs expectations.

\section{Sufficiently Protecting Contracting Authorities?}

The new minimum turnover limitation raises the question of whether it favours SMEs by neglecting the valid interests and concerns of contracting authorities. Contracting authorities and, consequently, public procurement processes need to be protected from possible illiquidity and financial distress of economic operators. In other words, by requiring too small a minimum turnover, contracting authorities expose themselves to a higher risk of procurement failure thus compromising the primary objective of procuring what they need to operate under the best possible terms. This can be particularly important if Article 58 (3) is interpreted as limiting the minimum turnover to twice the annual value of the contract, rather than its total value. ${ }^{97}$ The rationale for such interpretation would be that in many contracts SMEs would be unable to participate if the contracting authorities required the minimum of double the total value of the contract. Thus, favouring SMEs would suggest interpreting the rules as referring to annual value. However, this would be improper, as in cases of long-term public contracts requiring large investments SMEs with a sole double annual turnover will be most presumably unable to carry out the necessary investment and thus pose a risk to the execution of the entire procurement contract. Consequently, the Article 58 (3) should be interpreted as referring to the total value of the contract rather than the annual value.

To alleviate the potential risk coming with the new cap, Article 58 (3) enables contracting authorities to increase the requirement beyond the existing limitation in 'duly justified cases'. This refers to cases "such as relating to the special risks attached to the nature of the works, services or supplies". The wording of the provision is not very clear - the only certain aspect is that the exception shall be interpreted narrowly to avoid abuses of discretion. This argument is supported by the fact that contracting authorities "shall

97 Arrowsmith (n 32), 1192-1195.

98 Article 58(3) of Directive 2014/24/EU. indicate the main reasons for such a requirement in the procurement documents or the individual report referred to in Article 84." In other words, if a contracting authority wishes to apply more burdensome requirements regarding the yearly turnover of the economic operator, it needs to document its decision as well as reasons for taking it.

Furthermore, the turnover limitation shall be attuned in situations where the contract is divided into lots. In such cases, the contracting authorities

shall apply [the rule] in relation to each individual lot. However, contracting authorities may set the minimum yearly turnover that economic operators are required to have by reference to groups of lots in the event that the successful tenderer is awarded several lots to be executed at the same time. $^{98}$

If the contract is to be awarded on the basis of framework agreements or dynamic purchasing systems, the limiting turnover cap should be calculated on the basis of the expected maximum size of specific contracts. In cases of contracts divided into many lowvalue lots or awarded under a framework agreement with many economic operators, the cap limitation of twice the contract value may still be too high. Therefore, it is important to read the rules of Article 58 (3) in conjunction with Article 58 (1), so that established limitations are "strictly proportionate to the subjectmatter of the contract". That may lead to the conclusion that in particular cases setting a minimum turnover at twice the contract value may be disproportionate and it should be lower.

\section{Favouring SMEs?}

While larger companies also benefit from a lower minimum turnover requirement, they can normally meet higher requirements, so that the new cap clearly promotes SME participation. However, it is argued that minimum turnover requirements cannot be categorised as a provision that favours SMEs. This is because, firstly, even though Directive 2014/24/EU introduces higher risks for contracting authorities by setting a relatively low turnover cap, it provides contracting authorities with a 'protective shield' through the exception provision in 'duly justified cases'. Secondly, contracting authorities have other tools to mitigate the risk at their disposal, including a track 
record of previous successfully rendered services or previous economic indicators, such as ratios between assets and liabilities. A positive ratio showing higher levels of assets than of liabilities could provide additional evidence that the financial capacity of economic operators is sufficient. ${ }^{99}$ Thirdly, a certain level of protection is still provided by this minimum turnover requirement. Finally, it is argued that the higher risk of contracting authorities is compensated by the fruits of increased competition.

\section{Direct Payments to Subcontractors}

There are many SMEs which are perfectly capable to act as prime contractors and have been awarded and successfully performed public works, supplies, and services contracts. However, due to their limited size as well as technical and financial capacity many SMEs will be subcontractors in, at times, very long supply chains of large companies acting as prime contractors. There is a close connection between procurement rules promoting SME participation and procurement rules regulating subcontracting and the supply chain. Article 25 of the old Directive 2004/18/EC was very short on this matter by only requiring:

In the contract documents, the contracting authority may ask or may be required by a Member State to ask the tenderer to indicate in his tender any share of the contract he may intend to subcontract to third parties and any proposed subcontractors.

This information requirement was only complemented by a reference to prime contractor liability. ${ }^{100}$

\section{Bypassing the Prime Contractor}

However, Article 71(3) Directive 2014/24/EU was also introduced:

Member States may provide that at the request of the subcontractor and where the nature of the contract so allows, the contracting authority shall transfer due payments directly to the subcontractor for services, supplies or works provided to the economic operator to whom the public contract has been awarded (the main contractor). Such measures may include appropriate mechanisms permitting the main contractor to object to undue payments. The arrangements concerning that mode of payment shall be set out in the procurement documents. ${ }^{101}$

Thus, Member States can provide in their transposing laws that subcontractors are paid directly by the contracting authority rather than having to wait for payments from the prime contractor. This offers subcontractors, which are often SMEs, an efficient way of protecting their interest in being paid. However, not all subcontractors are SMEs and therefore this provision might equally benefit large companies when acting as subcontractors. Nevertheless, inter alia the Explanatory Memorandum to the 2011 Draft leading to the 2014 Directive clearly identifies this as one of four main measures to promote SME participation in public procurement. ${ }^{102}$

The July 2013 Draft and 2014 final text changed the wording of the 2011 Draft slightly as procedures permitting prime contractors to object to undue payments now only may be included, whereas in the 2011 Draft they had to be put in place. According to Article 71(7) of Directive 2014/24/EU Member States may "go further under national law on direct payments to subcontractors"; this can include a requirement for direct payments to subcontractors without them having to request them. Moreover, according to Article 71(8) Member States having chosen to provide for measures pursuant to inter alia Article 71(3) must specify the implementing conditions for those measures. Member States may limit the applicability of these implementing measures, "for instance in respect of certain types of contracts, certain categories of contacting authorities or economic operators or as of certain amounts." However, the general direct payment rule in Article 71(3), the possibility to go further in Article 71(7) on the one hand, and the possibility to limit the applicability of the rule on the other hand are options - Member States do not even have to implement the direct payment regime of the Directive at all, they can limit it and/or extend it. Regulation 113(3) UK Public Contract Regulations 2015, for example, while requiring quick payments down

99 Recital 83 of Directive 2014/24/EU.

100 Article 25(2) of Directive 2004/18/EC reads: "This indication shall be without prejudice to the question of the principal economic operator's liability."

101 Emphasis added.

102 Proposal for Procurement Directive (n 90). 
the supply chain, does not implement the direct payment regime of the Directive. Moreover, according to Article 71(3) of Directive 2014/24/EU, direct payments should only be provided "where the nature of the contract so allows." It appears that this is subject to the judgment of the contracting authority and the impact of this reservation will depend on factors such as the extent to which this discretion is regulated or generally the criteria that should guide this assessment. There is no guidance for this assessment provided in Directive 2014/24/EU. Moreover, this will depend on whether the judgment of the contracting authority can be challenged, especially in review proceedings.

The direct payment rule had been the only innovation to the subcontracting regime in the 2011 Draft Proposal. In the July 2013 Draft and the final 2014 Directive, Article 71 was significantly extended. However, it needs to be emphasised that the remainder of this subcontracting regime of the new Directive in its Article 71 (1)-(2), (4)-(6) and most of (8) of Directive 2014/24/EU does not promote the access of SMEs to public contracts as such. These paragraphs regulate issues such as ensuring that the social and environmental requirements applicable to prime contractors are also fulfilled by subcontractors, information requirements for prime contractors on their subcontractors, liability rules, and the qualification and exclusion of subcontractors. Therefore, the SME friend-

103 With regards to the promotion of SMEs through their access to public contracts by regulating subcontracting, the regime of Article 71 of Directive 2014/24/EU cannot be compared to that of Article 21 and Title III of the Defence and Security Procurement Directive 2009/81/EC, the latest procurement instrument before the 2014 reform. Directive 2009/81/EC contains four different options for subcontracting, including options involving the award of subcontracts through a notice in the OJ. Lord Young suggested a similar approach for the UK, but on a voluntary basis. The Lord Young report (n 18) reads: "Nine big public procurement suppliers have agreed to, where appropriate, advertise their subcontracting opportunities on Contracts Finder. SMEs should expect more to follow" (p. 43). However, the subcontracting regime in Directive 2009/81/EC is intended as a substitute for the now almost banned defence-specific practice of offsets (see M Trybus, Buying Defence and Security in Europe: The EU Defence and Security Procurement Directive in Context (Cambridge: CUP 2014), Chapter 9), a context not applicable to 'civil' public sector procurement. Moreover, the extensive subcontracting regime of the Defence and Security Directive 2009/81/EC might be of limited benefit in the context of Directives 2014/24/EU and 2014/25/EU and even Directive 2009/81/EC itself, an issue that cannot be explored further in this article. Nevertheless, the extensive subcontracting regime of Directive 2009/81/EC shows how far the EU legislator is prepared to go. In comparison, they did not go very far in the Directive 2014/24/EU.

104 Green Paper (n 66), 13: According to a figure (p. 5) 39\% of stakeholders wanted more control of subcontracting and this is also mentioned under "other issues" (p. 18). ly direct payment rule is simply part of a more detailed subcontracting regime in the new Directive. Only the optional information requirement on subcontractors in Article $71(2)$ and the related liability rule in Article 71(4) of Directive 2014/24/EU had already been contained in Article 25 of Directive 2004/18/EC. ${ }^{103}$

\section{Favouring SMEs?}

It is submitted that the direct payments to subcontractors do not favour SMEs adding to the costs or administrative burden or complexity to be shouldered by contracting authorities. During the consultation process, a majority of public authorities and civil society organisations favoured allowing public procurers to have more influence on subcontracting by the successful tenderer, while the other stakeholder groups rejected such a possibility. ${ }^{104}$ "Other stakeholders" will mainly refer to prime contractors and their opposition is understandable since a more detailed regulation of their subcontracting interferes with their freedom of contract. This opposition of prime contractors might imply a possible negative effect of the direct payments rule on competition as it might deter prime contractors. This could be interpreted as a cost for contracting authorities. However, there is no evidence for such an effect and this was not indicated in the Green Paper either.

The direct payment rule would also only add little to the complexity of the procurement process burdening contracting authorities. They would have to have a clear idea of the subcontractors and initiate payments but this complexity would arguably be too limited to be characterised as a rule that is favouring SMEs.

\section{Conclusions}

This article argued that none of the four innovations of Directive 2014/24/EU introduced to facilitate the participation of SMEs in public procurement can be classified as regimes favouring SMEs, to promote the participation of these economic operators to an extent that the primary objectives of efficient procurement, value for money, non-discrimination, and competition are significantly compromised. The division into lots will make procurement more complex for 
contracting authorities and cause them some costs, the ESDP will cause some costs and teething problems, the turnover requirement increases risk for contracting authorities, and the direct payment rule, if transposed, might irritate prime contractors. However, subject to transposition and actual practice, the costs and complications are limited and will be reduced over time and the potential increase in competition might well enhance value for money. There- fore, the four measures do not compromise the prime objectives of procurement but serve them to an extent. The promotion of SMEs as a sustainable goal is an added value of the 2014 reform - facilitating a secondary objective without compromising the primary objectives. Whether any of the four innovations are likely to actually meet their objective of increasing SME participation in public procurement is a different question for a different article. 